\title{
CLINICOPATHOLOGICAL STUDY IN A FEMALE INFANT WITH 46,XX,i(18q) SHOWING MIXED FEATURES OF BOTH TRISOMY 18 AND MONOSOMY 18p
}

\author{
Atsushi Ieshima, ${ }^{1}$ Sachio TaKashima, ${ }^{1}$ Kuniyasu TaKada, ${ }^{2}$ \\ Yumiko AKamatsu, ${ }^{3}$ Kyouichi OHTANI, ${ }^{3}$ and Goro ANDO ${ }^{3}$ \\ ${ }^{1}$ Divisions of Child Neurology and ${ }^{2}$ Neuropathology, Institute for Neurological \\ Sciences, Tottori University School of Medicine, Yonago 683, Japan \\ ${ }^{3}$ Department of Pediatrics, Tottori Prefectural Hospital, Tottori 680, Japan
}

\begin{abstract}
Summary Clinicopathological and cytogenetic findings in a female infant with $46, X X, i(18 q)$ were reported. She had mixed stigmata of both trisomy 18 and monosomy 18p. Most clinical and pathological findings in this case were compatible with trisomy 18 , but several findings such as round flat face, flat nasal bridge, large ears, short webbed neck, low posterior hair line and costovertebral anomalies were compatible with monosomy $18 \mathrm{p}$. Neuropathological study including Golgi study showed minimal dysmorphic abnormalities as seen in trisomy 18 .
\end{abstract}

\section{INTRODUCTION}

Isochromosome $18 \mathrm{q}$ is a rare condition and only 6 cases have been reported so far (Surana et al., 1973; Rodiere et al., 1977; Bass et al., 1979; Fioretti et al., 1982; Wulfsberg et al., 1984; Froster-Iskenius et al., 1984). Phenotype-karyotype correlations in patients with $\mathrm{i}(18 \mathrm{q})$ are not fully established. A male infant with i(18q) displayed mixed stigmata of both trisomy 18 and $18 \mathrm{p}$ - syndromes (Bass et al., 1979), but other cases with $\mathrm{i}(18 \mathrm{q})$ showed features of trisomy 18 . Autopsy findings of a fetus with $\mathrm{i}(18 \mathrm{q})$ have been reported (Froster-Iskenius et al., 1984), but neuropathological findings have not yet been reported. Here we report cytogenetic and clinicopathological findings including neuropathology in a female infant with $46, X X, 1(18 q)$.

\section{CASE REPORT}

The proband was the first child of healthy and unrelated 22-year-old mother and 26-year-old father. She was born at 41 weeks of gestation after normal pregnancy and delivery. Birth weight was $2,458 \mathrm{~g}$, the length $42.4 \mathrm{~cm}$ and the head 
circumference $33.5 \mathrm{~cm}$. The face was dysmorphic: flat round face, epicanthus, mongoloid slant, short saddle nose, carp mouth, micrognathia, low-set large ears, and prominent occiput. The neck was short and webbed. Low posterior hair line was

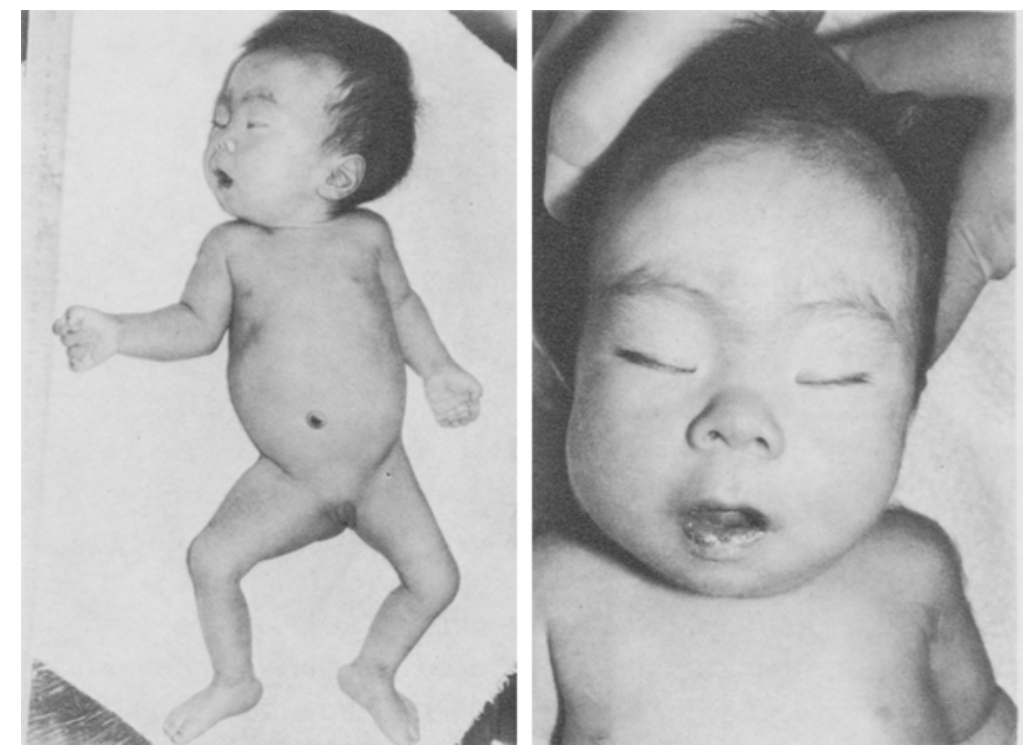

Fig. 1. Proposita at the age of 88 days.

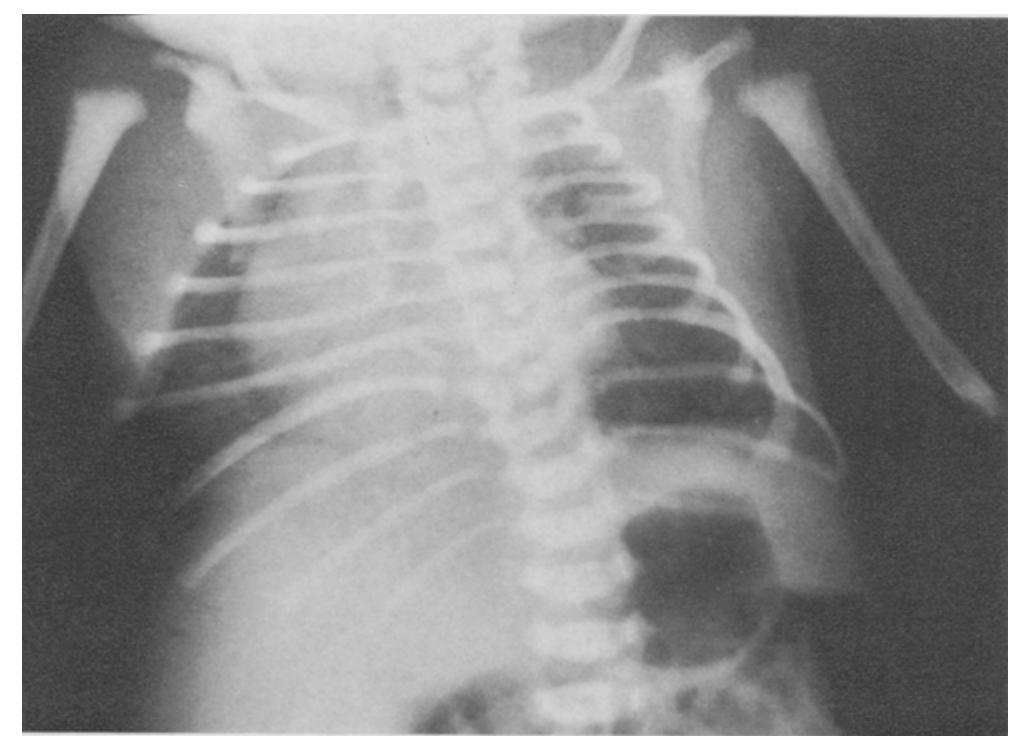

Fig. 2. Chest $X$-ray of the proposita. Note the multiple costovertebral anomalies and displacement of the mediastinum.

Jpn. J. Human Genet. 
noted on the nape. Short sternum, wide-set nipples, and diastasis recti abdominis was also noted. Pelvis was small and hip abduction was limited. Extremities were also dysmorphic: camptodactyly, overlapping fingers, single flexion crease of the fifth fingers and prominent calcaneus (Fig. 1). She had been suffering from cardiac failure, repeated hyperthermia and convulsions since three days of age, and died at 88 days of age.

Dermatoglyphics showed bilateral simian crease, ten arch patterns on the fingertips and axial triradii in the normal position.

Chest X-ray showed rightward displacement of the mediastinum and costovertebral dysplasia (Fig. 2). Cranial CT scanning was normal. Chemical and haematological laboratory data were normal. The Ig A value was $3.9 \mathrm{mg} / \mathrm{dl}$ at the age of 73 days.

The karyotype of the proband was determined to be $46, \mathrm{XX}, \mathrm{i}(18 \mathrm{q})$ using peripheral blood lymphocytes and skin fibroblast by G- and C-banding methods. Monocentric structure of the isochromosome could be revealed by C-banding method (Fig. 3). The karyotypes of the parents were determined to be normal by G-banding method.

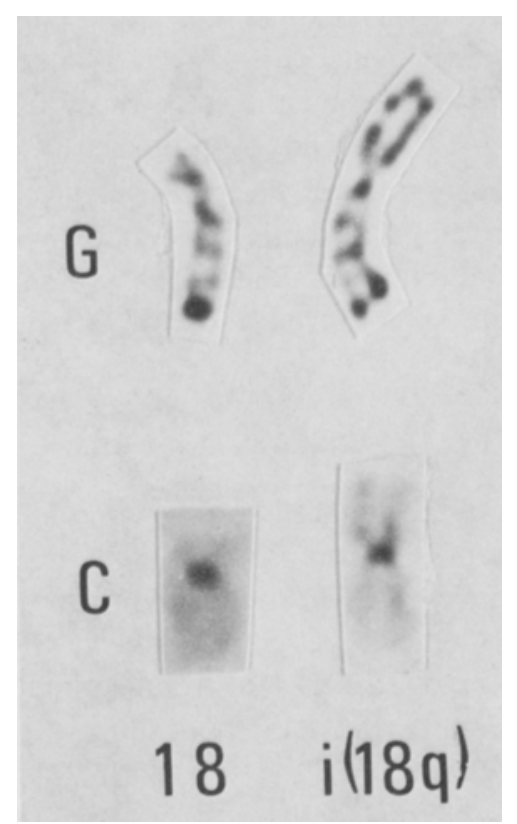

Fig. 3. Partial karyotype of the proposita, G-banding (upper, G) and C-banding (lower, C). 


\section{PATHOLOGICAL FINDINGS}

The pathological examination revealed cardiovascular anomalies (coarctation of aorta, pulmonary stenosis and poly-valvular anomalies), costovertebral anomalies (7 ribs, fused ribs and hemivertebrae), malrotation of the intestine, Meckel's diverticulum and mild hydronephrosis. Histologically there were bronchopneumonia in both lungs and thickening of pulmonary arterial walls. The kidney had numerous immature glomeruli, the thin cortex and cystic dilation of tubules.

Neuropathologically the brain was dolicocephalic and small, weighing $475 \mathrm{~g}$. There were no gross morphological anomalies except for hypoplastic temporal lobes. On microscopic examination, minor morphological anomalies were noted. The hippocampus formation had hypoplasia of the granular cell layer which was abnormally convoluted and terminated in a dimunitive fascia dentata. CA3 was thick and the hilus of the fascia contained an excessive number of neurons (Fig. 4a). The degree of subcortical white matter myelination was poor for age, and the corpus callosum was thin. The lateral geniculate body had an irregular lamination. The inferior olivary nuclei had thick dorsal lamellae which were incompletely folded and a layer of neurons delimiting the periphery of each lamella (Fig. 4b).

Rapid Golgi stains using fresh brain tissues were performed on the right visual cortex, cerebellar cortex and cervical spinal cord, and compared with those of agematched normal control, and patients with trisomy 18 and Down syndrome. There was normal neuronal arrangement, but the some of pyramidal neurons were small, and basilar dendrites were short and poorly branched (Fig. 5). Some basilar dendrites had varicosities. The number of spines was smaller and the shape of spine was thin and long, Dendric trees of Purkinje cells were hypoplastic and dendrites of spinal anterior horn cells had long-thin spines. These findings were also observed in patients with trisomy 18 , but differed from those of Down syndrome.

\section{DISCUSSION}

Isochromosome $18 \mathrm{q}$ is a rare condition and represents trisomy $18 \mathrm{q}$ and monosomy $18 \mathrm{p}$. The phenotype of isochromosome $18 \mathrm{q}$ can be supporsed to combine the features of the trisomy 18 and $18 \mathrm{p}$ - syndromes. However, the majority of cases with i(18q) displayed trisomy 18 phenotype (Surana et al., 1973; Rodiere et al., 1977; Fioretti et al., 1982; Wulfsberg et al., 1984). A male infant with i(18q) displayed the features of trisomy 18 as well as those of monosomy $18 \mathrm{p}$ such as depressed nasal bridge, round face, short webbed neck, low posterior hair line and widely-spaced nipples (Bass et al., 1979). A female fetus with i(18q) represented trisomy 18 phenotype (Froster-Iskenius et al., 1984), but slightly modified with the features of monosomy 18 p including a short webbed neck.

Present case also showed features of both the trisomy 18 and $18 \mathrm{p}-$ syndromes. The features of monosomy $18 \mathrm{p}$ were mainly represented in facial dysmorphism such 


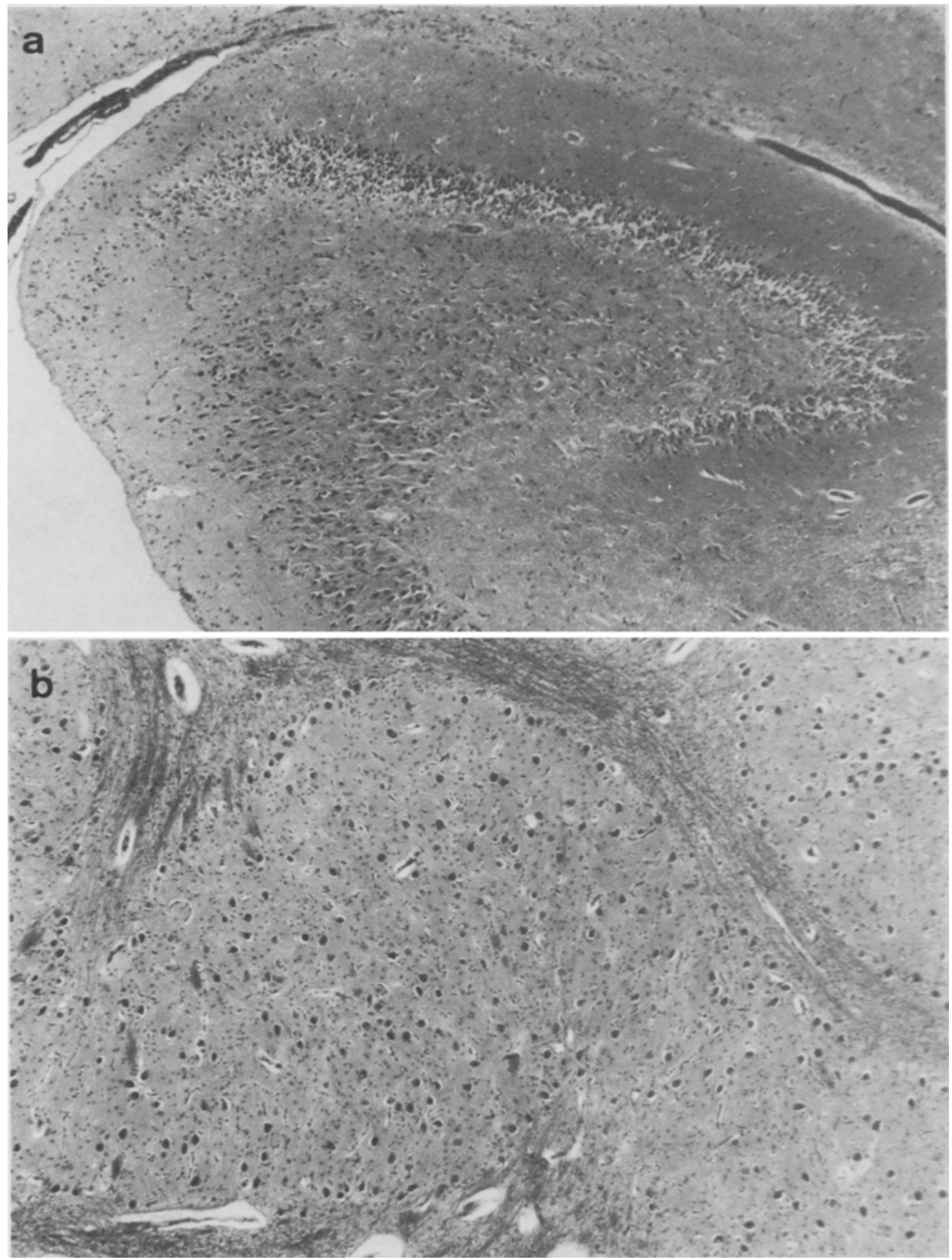

Fig. 4. a. Hippocampus. (HE stains, $\times 40$ ) b. The inferior olivary nuclei. (KluverBarrera stain, $\times 100$ ) 

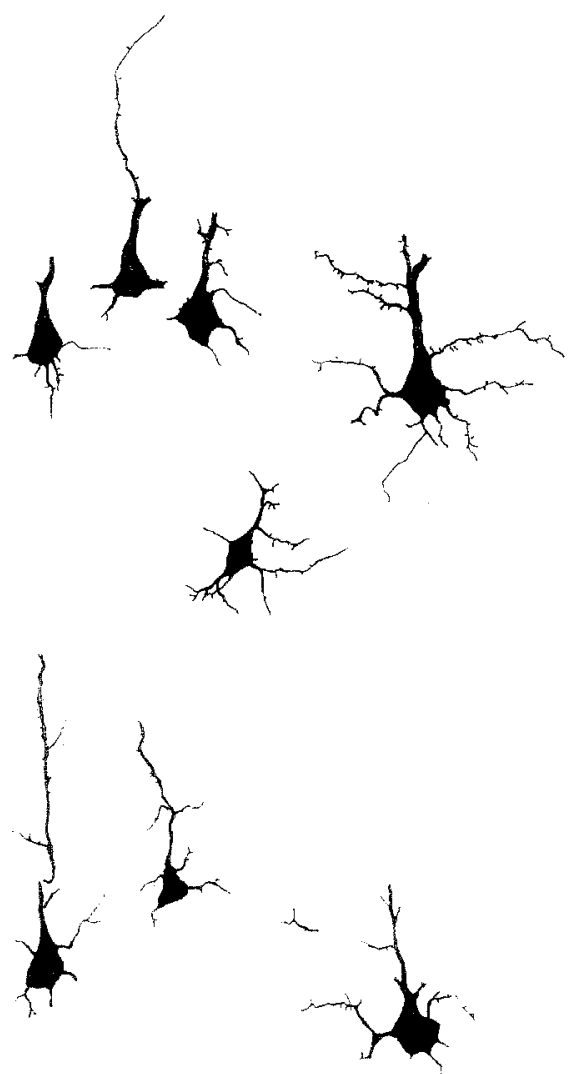

Fig. 5. Camera lucida drawings of pyramidal neurons (layer 3 and 5) in the visual cortex (Golgi stain)

as large ears, fiat nasal bridge, round face, carp mouth, short webbed neck and low posterior hair line. Costovertebral anomalies were compatible with the features of monosomy 18p (Nakano et al., 1977). Other external anomalies as well as pathological anomalies were all compatible with features of trisomy 18 (de Grouchy and Turleau, 1977).

Isochromosome $18 \mathrm{q}$ can be divided into two groups; monocentric $\mathrm{i}(18 \mathrm{q})$ and dicentric $1(18 q)$. Patients with dicentric i(18q) represented clinical features of trisomy 18 (Fioretti et al., 1982; Wulfsberg et al., 1984). Whereas, patients with monocentric i(18q) mostly displayed the features of trisomy 18 , but combined with the features of monosomy 18p, more or less (Bass et al., 1979; Froster-Iskenius et al., 1984; present case). The features of monosomy $18 p$ in patients with monocentric $i(18 q)$ may be partially expressed because of monosomy for $18 \mathrm{p} 11$ band. Thus, isochromosome $18 \mathrm{q}$ may be divided into two clinical entities. However, more cases must be collected before establishing karyotype-phenotype correlations in isochromosome 18q.

Autopsy case with $\mathrm{i}(18 \mathrm{q})$ is rare and neuropathological studies have not been 
reported. The autopsy findings in a fetal case with monocentric i(18q) were compatible with those of trisomy 18 (Froster-Iskenius et al., 1984). In our case gross morphological anomalies were also all explained as features of trisomy 18.

In neuropathological studies, there were abnormal changes such as hypoplasia of temporal lobe, dysplasia of hippocampus, irregular lamination of lateral geniculate body, incomplete folding of the inferior olivary nuclei, hypoplasia of corpus callosum and poor myelination in the white matter. These findings are frequently seen in the cases of trisomy 18 (Sumi, 1970; Michaelson and Gilles, 1972).

Golgi study in Down syndrome or trisomy 13 demonstrated the morphological abnormalities of dendrites or their spines in the cerebral cortex (Marin-Padilla, 1972, 1974; Takashima, 1980; Takashima et al., 1981). Golgi study of our case showed poor branchings of dendrites in the cortical pyramidal neurons and spinal anterior horn cells. In addition, the number of spines was small, and the shape of spines was thin and long. These dendritic abnormalities were also seen in our 6month-old infant with trisomy 18 . These dendritic abnormalities are not specific. The abnormal spine shape is also found in the cases with trisomy 13 or 21 syndromes. These morphological changes of dendrites and spines may be related to synaptogenesis and cerebral hypofunction in some of chromosome aberrations.

Acknowledgement We are indebted to Prof. Kenzo Takeshita and Prof. Haruomi Nakamura, Divisions of Child Neurology and Neuropathology, for their encouragement and aid in preparation of the manuscript.

\section{REFERENCES}

Bass, H.N., Sparkes, R.S., and Miller, A.A. 1979. Features of trisomy 18 and $18 \mathrm{p}-$ syndromes in an infant with 46,XY,i(18q). Clin. Genet. 16: 163-168.

Fioretti, G., Stabile, M., Pagano, L., Rinaldi, A., Rolando, D., Trapassi, C., Tollis, G., and Ventruto, V. 1982. A case of Edward's syndrome with pseudodicentric isochromosome 18: 46, XY, i dic (18) (p11::p11). Ann. Genet. 25: 116-118.

de Grouchy, J. and Turleau, C. 1977. Clinical Atlas of Human Chromosomes. John Wiley \& Sons, Inc., New York, pp. 159-180.

Froster-Iskenius, U., Coerdt, W., Rehder, H., and Schwinger, E. 1984. Isochromosome 18q with karyotype 46,XX,i(18q). Cytogenetics and pathology. Clin. Genet. 26: 549-554.

Marin-Padilla, M. 1972. Structural abnormalities of the cerebral cortex in human chromosomal aberrations: a Golgi study. Brain Res. 44: 625-629.

Marin-Padilla, M. 1974. Structural organization of the cerebral cortex (more area) in human chromosomal aberration. A Golgi study. 1. D(13-15) trisomy, Patau syndrome. Brain Res. 66: 375-391.

Michaelson, P.S. and Gilles, F.H. 1972. Central nervous system abnormalities in trisomy E(17-18) syndrome. J. Neurol. Sci. 15: 193-208.

Nakano, S., Okuno, T., Hojo, H., Misawa, S., and Abe, T. 1977. 18p- syndrome associated with hemivertebrae, fused ribs and micropenis. Jpn. J. Human Genet. 22: 27-32.

Rodiere, M., Donadio, D., Emberger, J.M., Astruc, J., and Brunel, D. 1977. Isochromosome $18: 46, \mathrm{XX}, \mathrm{i}(18 \mathrm{q})$. Ann. Pediatr. 24: 611-616.

Sumi, S.M. 1970. Brain malformations in the trisomy 18 syndrome. Brain 93: 821-830. 
Surana, R.B., Mckendry, J.B., Bailey, J.D., and Conen, P.E. 1973. Isochromosome long arm 18. Am. J. Hum. Genet. 25: 77, A.

Takashima, S. 1980. Neuronal development of the fetal and infantile period: 1. Visual cortex in the normal and chromosomal aberrations. Brain Nerve (Domestic Ed.) 32: 1007-1013.

Takashima, S., Becker, L.E., Armstrong, D.L., and Chan, F. 1981. Abnormal neuronal development in the visual cortex of the human fetus and infant with Down's syndrome. A quantitative and qualitative Golgi study. Brain Res. 225: 1-21.

Wulfsberg, E.A., Sparkes, R.S., and Klisak, I.J. 1984. Trisomy 18 phenotype in a patient with an isopseudodicentric 18 chromosome. J. Med. Genet. 21: 151-153. 